\title{
Das Bases para um Nồo Plano de Classificação de Cargos no Brasil
}

\author{
Fenelon Silva
}

\section{INTRODUÇÃo}

$A_{\text {filosofia da classificação de cargos assenta-se nos seguintes }}$
principios: (1)

19) para que as funções públicas possam ser desempenhadas igual e eficientemente, é preciso que a totalidade dos cargos seja organizada mediante um plano bem delineado; quer dizer, os cargos semelhantes devem ser grupados numa mesma classe, com título e definição próprios e cada cargo individual deve identificar-se com a respectiva classe, passando a ser conhecido pela denominação dada a esta classe;

2.) a base para a classificação deve ser as atribuições e as responsabilidades habituais dos cargos; assim, o plano resultante da classificação dos cargos será da mais absoluta utilidade para a administração de pessoal.

Do ponto-de-vista da administração, cargo é o conjunto de encargos e responsabilidades atribuidos ou delegados pela autoridade competente a uma pessoa, exigindo, desta, tempo integral ou parcial de trabalho. $O$ cargo pode ser temporário ou permanente, ocupado ou vago e é criado por lei.

Os cargos caracterizam-se a qualquer momento, exclusivamente, pelas suas respectivas atribuições e responsabilidades, tais como existem na ocasião. Enquanto êsses atributos permanecerem os mesmos, o cargo permanecerá também o mesmo, a despeito de quaisquer outras considerações.

As atribuições e responsabilidades dos cargos nem sempre permanecem fixas ou imutáveis; modificam-se vez por outra,

(1) IsMar Baruch - Folheto $n^{\circ} 10$ da «Civil Service Assembly», dos Estados Unidos da América e do Canadá - 1937 . 
abrupta ou gradativamente, por múltiplas e diferentes razões. Verificada a modificação nas atribuições ou responsabilidades do cargo, procede-se à criação de nôvo cargo, que será diferente do antigo na proporção da modificação realizada.

Plano de Classificação de Cargos é um sistema segundo o qual os cargos, na base das respectivas atribuições e responsabilidades habituais, são grupados em classes, cada classe designada por um título descritivo, êste, por sua vez, definido por uma especificação de atribuições, responsabilidades, tarefas típicas e exigências de qualificação. O plano deve conter um código de regras para a respectiva manutenção, alterações e correções correntes.

Plano de vencimentos ou de remuneração, por outro lado, é um plano pelo qual os cargos, já distribuídos de acôrdo com o plano de classificação, são escalonados por classes, em relação uns com os outros, e dentro do qual um código de regras formais e básicas regula a sua instalação, administração, desenvolvimento e adaptação, particularmente as normas que autorizam e controlam alterações na remuneração das classes de cargos e respectivos ocupantes.

Em outros têrmos: um plano de classificação de cargos serve para separar os cargos em classes; um plano de vencimentos serve para fixar a escala de salários para cada classe e cada cargo, bem como o nivel de retribuição para cada funcionário em determinada época.

São fatôres básicos, de modo geral, quanto aos planos de remuneração:

10) fatôres determinantes da política da remuneração na jurisdição e do nivel geral de remuneração considerada coletivamente;

29) fatôres determinantes dos niveis relativos de remuneracão entre classes e fixadores dêsses niveis quanto aos cargos individuais.

O processo de classificacão, de modo geral, consiste em distribuir coisas em classes. As coisas que se assemelham em um ou mais aspectos, arupam-se numa mesma classe, e em classes diferentes, as que diferem entre si nesses aspectos.

Qualquer processo de classificacão deve abranger, irrecusàvelmente, definicão e nomenclatura sistemática. As várias classes usadas no processo devem ser identificadas por nomes, números ou simbolos que sirvam de meios normais de comunicação.

Cada classe deve ser descrita ou definida de modo que indique seu conteúdo e respectivos limites. As definicões atribuem a cada classe um nome, um número ou um simbolo de significação padro- 
nizada e uniforme que sirva para referências futuras e de tal forma que, quaisquer novos itens que venham a surgir, possam ser classificados da mesma forma que os primeiros.

Antes de se classificar um conjunto de coisas, convém decidir em que base se fará a classificação. Esta base deve referir-se a alguma caracteristica, qualidade, atributo on combinação dêstes, no tocante aos quais as coisas a serem classificadas se assemelhem ou difiram entre si.

Os cargos podem ser semelhantes ou diferentes, relativamente a vários tipos de características ou atributns e por isso podem ser classificados dentro de bases diferentes. Mas dentro da finalidade a aue se destina o plano só há uma hasa fundamental nara a clas sificação de cargos: ATRIBUIÇŌES E RESPONSABILIDADES dos cargos.

Constitui um equivoco pensar-se que, na classificação de um cargo, deve-se dar especial importância à capacidade, às qualidades e à eficiência de seu ocupante e que cada funcionário imprime ao cargo sua personalidade e os cargos raramente serão os mesmos, se ocupados por diferentes individuos. O que se classifica são os cargos e não os funcionários que os ocupam: a classificação dos funcionários segundo suas qualificações e habilitações só tem utilidade quando se trata de designações para postos de comando ou
de graus para o merecimento.

Se os cargos fôssem grupados em classes segundo as qualificações dos seus ocupantes, o nivel de vencimentos para cada classe se aplicaria a todos os ocupantes dentro dessa classe e tôdas as pessoas com as mesmas qualificações ou qualificações correspondentes, receberiam a mesma remuneracão. Então, um individuo que executasse tarefas fáceis e rotineiras teria os mesmos vencimentos que outro que executasse tarefas difíceis e de responsabilidade. simplesmente porque ambos têm as mesmas qualificações ou
qualificaçoses correspondentes.

A remuneração deve ser para o trabalho executado e não para as qualificações que o funcionário possa ter, desde are não são anroveitadas nem necessárias na execucão dêsse trabalho. A classificacão de carqos, portanto, serve de base para o nivelamento e padronização dos vencimentos. Para se consequir classificacão apropriada, pois, faz-se necessário frisar a distincão entre as características de um carqo e as caracteristicas que o respectivo
ocupante nossa ou não ter.

A existência de um carro e sua identidade não denendem de ser êle ocunado ou não. Muitas vêzes existe como vađo antes de ser ocupadn por alquém e volta a estar vaqo d11ando o respectivo ocunante dêle se afasta. O conceito de cargo é distinto do conceito
de funcionário. 
No serviço público, de modo geral, a fixação da politica de remuneração e escala de pagamentos é da competência do legislativo, ao passo que a classificação de cargos é função eminentemente executiva. Sempre que houver essa espécie de divisão, é de especial importância reconhecer-se que a consideração e apreciação de certos fatôres cabem ao legislativo, para a determinação dos assuntos relativos à remuneração, e que não cabe ao órgão classificador considerá-los na classificação de cargos individuais.

\section{1 - HISTÓRICO}

\section{1 - Inglaterta (2)}

O sistema de mérito mediante concurso competitivo, para o ingresso no serviço público inglês e na India, foi ali introduzido em 1853, depois de vinte anos de estudos e debates provocados por um relatório de Macaulay. Nesse relatório, Macaulay acentuou que os servidores civis da Companhia da India deveriam entrar para a carreira quando ainda bem jovens e trazer consigo uma educação liberal completa, pois que a experiência já provara que êste tipo de educação constituiria a melhor preparação para o exercício de qualquer função que exija altos pendores vocacionais.

Uma curiosidade interessante dêsse relatório é a que acentuou MaCAULAY, afirmando que pessoas dedicadas durante anos a estudos que não se relacionem com qualquer profissão ou negócio e que. por isso mesmo, estão em condiçōes de robustecer e enriquecer o espirito, são, geralmente, superiores em qualauer profissão ou função do que quaisquer outras que aos 18 ou 19 anos se dedicaram exclusivamente a estudos específicos da sua profissão. Este pensamento constitui o fundamento filosófico do sistema de classificação de cargos na Inglaterra.

Implantando o sistema do mérito destinado a selecionar funcionários entre $1853 / 54$, ficou também criado o sistema de carreiras no serviço público inglês e na Índia.

Assim. o relatório Macaur.ay lançou as bases do recrutamento em condicões tais que o candidato devia medear de 17 a 24 anos. caracteristica esta que ainda hoie peculiariza as classes gerais de servidores do Tesouro Britânico.

A partir de 1920. a classificacão de carcos na Inglaterra está intimamente ligada ao sistema educacional do país, pois as disci-

(2) PAulo Poppe de Figueiredo - Classificação de Carơos na Inglaterra - In Revista do Serviço Público, janeiro de 1952 - pág. 17. 
plinas exigidas nos concursos são as mesmas ministradas nas escolas e universidades. conforme as classes em que ocorre o recrutamento.

Com a instituição generalizada do sistema do mérito na GrãBretanha, um nôvo decreto de 1870 estabeleceu a norma de concurso competitivo e geral como método normal, mas não exclusivo, de ingresso no serviço civil inglês, concurso que se tornou o sistema estandardizado de recrutamento a ser feito para dois grandes grupos: Classe I ou intelectual, seleção de candidatos com educação universitária: Classe II ou de rotina, para candidatos correspondentes ao currículo secundário. Estas duas classes ainda hoje marcam o principal ispecto, representam mesmo o verdadeiro serviço civil inglês.

Desta forma, os ocupantes de cargos administrativos passam a ter oportunidade de galgar os postos mais elevados da administração; os jovens escolhem, de preferência, o serviço público como profissão para o resto da vida. Mesmo para os que não concluiam o curso secundário, estava aberta a possibilidade de fazer carreira no serviço civil ingressando como auxiliar de escrita; os universi tários inclinavam-se para o clero, marinha, exército ou para o serviço público.

Na Inglaterra, como se vê, a classificação de cargos é secular, fazendo-se a distribuição do pessoal pelas classes, segundo as habilitações exigidas de cada funcionário na ocasião do seu ingresso no serviço público britânico. Não há ali um plano de conjunto, tendo-se constituído as classes em correspondencia com as etapas da educação dos candidatos, mas a classificação vertical não deixa de existir em graus sucessivos de responsabilidade e dificuldade
dos cargos.

Por outro lado, a administração de pessoal na Inglaterra está organizada dentro do principio de ampla divisão de trabalho, de tal forma que as funções administrativas do govêrno se agrupam em grandes setores, cada um dos quais recruta seus elementos em niveis específicos do sistema educacional.

Mas o sistema de cargos da administração de pessoal da Inglaterra não apresenta esta simplicidade aparente; ao lado destas classes amplas e gerais de natureza administrativa, há outras fora do esquema traçado pelo citado Relatório. Em conjunto, em perspectiva geral o sistema de cargos inglês é complexo.

Paralelamente a um todo organizado e regido por normas padrões, representado pelas classes do Tesouro, há outro grupo que, gradativamente, se valoriza, dada a sua finalidade especifica e técnica. As classes que compóem êste segundo grupo são deno- 
minadas de "classes departamentais". Em esbôço sumário, o sistema de cargos no serviço público civil inglês é o seguinte:

\section{I - Classes Gerais ou do Tesouro}

Classe administrativa

Classe executiva

Classe de escriturários

Classe de auxiliares de escrita

Classe de datilógrafos e taquigrafos

\section{II - Classes Departamentais}

Classe erecutiva

Classe ae escriturários

Classe de datilógrafos

Classe de fiscais de impôsto de consumo, exatores e coletores

Classe de inspetores

Classe profissional, técnica e cientifica

Classe subordinada de supervisão e técnica

Classe de manipuladores (pessoal dos Correios)

Classe industrial

Classe de mensageiros, carregadores e de limpeza.

As classes do Tesouro são padronizadas e obedecem a um conjunto de regras uniformes; as classes departamentais se organizam diferentemente.

A classe administrativa correspondia, antes de 1920 , à dos escriturários, denominada de $1^{\text {* }}$ classe, e se destinava a funções de caráter elevado que requeria esfôrço criador e pendor de direção. Representa o núcleo do serviço civil inglês que reúne os melhores cérebros selecionados das universidades; para ela estabeleceu-se dupla fonte de recrutamento: dentro do próprio serviço e fora dêle.

Cabem a esta classe deveres da mais alta responsabilidade administrativa; entre êstes, destacam-se os que dizem respeito à formação da política administrativa, à coordenação e ao aperfeiçoamento da organização, à administração geral e à direção dos serviços do Govêrno.

A nomeação para o nivel inicial desta classe não é exclusiva de pessoal com formação universitária; está aberta a todos os funcionários já vinculados ao serviço civil inglês, que deram cedo provas de real habilidade e promessa de que poderão, mais tarde, desempenhar, satisfatòriamente, altos cargos de administração. O pessoal recrutado de dentro ou de fora constitui o corpo de cadete sujeito a estágio probatório de dois anos, durante os quais é submetido a intenso treinamento. 
A classe administrativa abre oportunidade a que se galguem os postos mais elevados da administração pública, mediante promoção dêstes niveis:

1 - Assistente principal

2 - Principal

3 - Assistente de secretário

4 - Assistente principal de secretário.

5 - Vice-secretário permanente

6 - Secretário permanente

Ingressando como cadete, no nivel de assistente principai, o funcionário terá ensejo de subir até secretário permanente, pôsto mais elevado do serviço administrativo inglês, apenas inferior aos cargos de ministro e secretário particular, que são de natureza
politica.

O meio de acesso é a promoção; quando assistente principal, o funcionário desempenha deveres iniciais da carreira; como principal, já está apto a chefiar seções ou dirigir divisões e serviços. Como assistente de secretário ou assistente principal de secretário, integra órgãos de "staff". Dirige grandes departamentos, quando assistente principal de secretário. O vice-secretário permanente é substituto do secretário permanente.

O estudante, ao ser nomeado assistente principal, logo ao deixar a universidade, não está em condições de arcar cum os deveres funcionais do cargo, pois não há relação alguma entre as disciplinas gerais e clássicas do seu concurso e os conhecimentos práticos e especializados da carreira. Dai a necessidade de um sistema intenso de treinamento no serviço que o prepare, tècnicamente, para exercer com eficiência as atribuições que lhe competem.

O curriculo das velhas universidades inglêsas versa sôbre clássicos e ciências exatas. Das ciências sociais, apenas história, direito e, de modo restrito, economia. Sociologia e disciplinas sôbre
administração são desconhecidas.

Portanto, o candidato universitário ingressa no serviço público com excelente "background" clássico e humanista, mas não tem formação especializada ou técnica e ignora matérias sôbre organização, administração em geral e métodos de trabalho. O treinamento é que irá suprir esta lacuna, realizando no serviço a formação
profissional. Classe Executiva - A classe administrativa se distingue como
um todo bem caracteristico; cabem-lhe as funcolo assessoramento, coordenação cabem-lhe as funções de supervisão, administrativa, configurando, planejamento e formação da politica As demais classes do Teso a segunda das duas grandes divisões. 
destinam a trabalhos administrativos de responsabilidade e formas diferentes, fundamentalmente, trabalhos de aplicação e execução com base em regulamentos, decretos e decisões bem definidos. Não realizam tarefa criadora.

A classe executiva se encontra, geralmente, em serviços de material e contabilidade e desempenha variado conjunto de funções dentre as quais ressaltam as atuariais, as jurídicas, as de exame e contrôle de despesas, as estatisticas, as contábeis, ou de suprimento de material.

Há dois graus nesta classe: o de treinamento ou júnior e o superior ou sênior. O júnior realiza exame crítico de casos e problemas individuais de menor importância, não previstos claramente em regulamentos e decretos, faz investigações preliminares sôbre assuntos de importância maior e dirige pequenas seções do serviço; o sênior se dedica às questões de organização interna e de contrôle, procurando solucionar problemas complexos e assume responsabilidade da direção de importantes trabalhos.

O recrutamento para esta classe ou ocorre entre os funcionários da classe dos escriturários, que deram provas cedo de habilitação e capacidade para o exercício de funções mais elevadas, realizando o recrutamento interno, ou ocorre entre os jovens de 18 a 19 anos, mediante concurso aberto e competitivo em que o nivel das disciplinas se relaciona com o curriculo correspondente à conclusão do curso secundário.

Ao lado da classe executiva do Tesouro, há outra do mesmo nome nos departamentos submetidos a regime de recrutamento e treinamento especifico consoantes o órgão ou repartição.

Classe dos Escriturários - As promoções desta classe para a executiva decorrem do fato de que os onciais executivos chetiam os escriturários e que não há, na prática, diterença fundamental da natureza do trabalho entre uma e outra classe, mas, simplesmente. graus diferentes de responsabilidade.

A classe dos escriturários cabem atribuições administrativas mais simples, não incluídas entre as da alçada da classe imediatamente inferior de auxiliar de escrita, cuidando do exame de casos e questôes individuais em face das normas, regulamentos ou prática adotada. Examina e verifica contas, faturas, empenhos, reclamacões; colige dados e material para elaboração de relatórios. estatisticas, pareceres e decisões. Assume a supervisão do trabalho da classe imediatamente inferior.

O recrutamento mediante concurso aberto e competitivo se faz entre jovens de 16 a 17 anos com instrução correspondente ao padrão de ensino alcançado no estágio médio do curso secundá- 
rio. Há dois graus: o inferior e outro mais elevado. Os ocupantes dêste último, já capazes e experimentados, poderão exercer funções de chefiar setores em que trabalhem auxiliares de escrita ou desempenham atribuições da competência do grau inicial da classe executiva.

Ao lado da classe dos escriturários do Tesouro, há outra do mesmo nome dos departamentos; ambos se recrutam através de concursos e promoção, obedecendo ao mesmo limite de idade e são exigidos niveis de instrução correspondente.

A Classe de Auxiliar de Escrita lida com máquinas de perfuração, de calcular e de contabilidade; faz serviços de cópia e de transcrição, de aposição de endereços. Examina simples documentos, distribui e prepara relações e esquemas, preenche fichas e cuida de fichários indices.

Deriva esta classe da anterior (writing assistant) e é reservada exclusivamente às mulheres; encontra-se nos serviços de rotina em que há trabalho mecânico. Quando não há êste tipo de trabalho, os auxiliares de escrita são substituídos pelos ocupantes de
nivel inicial da classe supertor.

O recrutamento externo é entre 16 e 17 anos e por meio de concurso geral e competitivo; há uma peculiaridade na seleção dêste pessoal: dado o seu baixo nível de salário, é êle de caráter local. O candidato apenas pode inscrever se em localidades que não dis-
tem um dia de viagem do seu domicilio.

Os seus ocupantes geralmente passam a escriturários; o tipo de trabalho - rotineiro e monótono - não permite julgamento cabal da eficiência dos funcionários. Esta dificuldade de apurar o merecimento levou algumas repartições a submeter, para efeito de promoção, a uma prova de escriturários os que já alcançaram antiguidade para acesso ou os que se mostram capazes para assumir deveres mais elevados.

Classe de Datilógrafos e Taquigrafos-Datilógrafos - Embora o trabalho que realizam tenha conexão direta com as classes administrativas e executiva, caracterizam-se como um grupo homogêneo e especifico, sem grande dificuldade de identificação. Há
os niveis ou graus seguintes:

Datilógrafo

Taquigrafo-datilógrafo Superintendente

Superintendente-chefe

O recrutamento constitui exceção marcante à regra geral dos concursos adotados para as demais classes do Tesouro, baseados em provas cuja natureza corresponde às disciplinas dadas a vários 
O candidato a Datilógrafo, entre 18 e 28 anos, passa por um concurso aberto e competitivo; concomitantemente aos conhecimentos gerais, devem demonstrar habilidade em prova prática de datilografia. O mesmo ocorre com os pretendentes à classe de Taquigrafo-datilógrafo que, além de provas de conhecimentos gerais e de datilografia, devem passar por uma seleção taquigráfica. O recrutamento para esta classe é entre 19 e 40 anos, tirando-se o pessoal internamente entre os servidores com mais de três anos de serviço em determinados cargos permanentes ou provisórios.

A combinação datilógrafo-escriturário ou taquígrafo-escritutário indica classes existentes em serviços departamentais, não incluídos nas do Tesouro, servindo, geralmente, em regiões afastadas da capital.

A Classe Profissional, Técnica e Cientifica está fora do Tesouro, seleciona o pessoal especificamente: os candidatos provêm de fora do serviço, preenchem requisitos próprios. Em geral, devem ser membros de alguma sociedade, associação ou instituto que exijam dos membros a condição de portador de diploma universitário. As vêzes, os candidatos, quando nomeados, são submetidos a um treinamento no serviço.

Os candidatos a cargos jurídicos se recrutam por meio de entrevistas competitivas, realizadas por uma comissão especial; dá-se o mesmo com os médicos que, ademais, precisam estar inscritos no Registro Médico Geral. Os arquitetos e engenheiros, outrossim, para serem nomeados, devem provar a qualidade de membros, aquêles do Real Instituto dos Arquitetos Britânicos e êstes da Instituição de Engenheiros Civis, Instituição de Engenheiros Mecânicos e Instituição de Engenheiros Eletricistas.

Os técnicos, cientistas e profissionais do serviço civil inglês não têm oportunidade de ascender aos postos mais elevados da administração pública, como ocorre com os funcionários do serviço administrativo. Esta situação é, realmente, desigual, principalmente sabendo-se que se trata de grupo de funcionários altamente qualificados.

O sistema de pessoal civil inglês implica articulação do Tesouro com a Comissão do Serviço Civil, estabelecimentos oficiais e conselhos. Na Inglaterra, a Comissão do Serviço Civil limita-se a realizar concursos e expedir certificados de habilitação. Mesmo dentro de sua competência específica, a Comissão sofre restrições: precisa de autorização do Tesouro para decidir o tipo de recrutamento dos concursos (se aberto, se fechado), especificar as condições em que se deve expedir o certificado de habilitação, determinar as condições do concurso e períodos de realização, reservar, 

certos cargos, para candidatos do sexo masculino, regular exames
para mulheres e criar exceçnes.

O Tesouro, além de opinar em matéria de seleção, tem ampla autoridade em outros assuntos de pessoal; a partir de 1920, esta autoridade dominou, cabendo-lhe dispor sôbre classificação, planos de pagamento e condições de serviço.

As Divisões do Tesouro gozam de autoridade para tratar e dispor sôbre a administração de pessoal, excetuando apenas os concursos realizados pela Comissão do Serviço Civil.

O sistema de pessoal inglês se completa com os estabelecimentos oficiais nos Ministérios e grandes departamentos responsáveis pela supervisão do estágio probatório, promoção, transferência, aposentadoria, dispensa, métodos e processos de trabalho e cadastros em geral. Estes estabelecimentos articulam-se com o Tesouro, estabelecendo um regime de contatos de administração de pessoal do Ministério ou depertamento a que pertence.

Em resumo, a administração de pessoal na Inglaterra está organizada dentro de sistema complexo de órgãos que se articulam e coordenam, cabendo o recrutamento à Comissão do Serviço Civil; - conhecimento e decisões sôbre outras fases de pessoal ao Tesouro, assessorado por uma comissão permanente; a aplicação e execução dos regulamentos e decretos aos ministérios e departa-
mentos por meio dos estabelecimentos oficiais.

Conclusão: na administração de pessoal inglêsa articulam-se três grandes sistemas: o educacional, o de recrutamento e o de

O sistema de mérito, instituido genèricamente em 1870, intei pré-estabele relaciona com o sistema educacional do país; a idade determina o sentido base nas idéias do relatório Macaulay. didatos se submetem a concionalização da carreira, pois os canescolares, como se vê:

Classe de auxiliar de escrita Idade

Classe de escriturário $\ldots \ldots \ldots \ldots \ldots, 16-17$

Classe executiva ................. $16-17$

Classe administrativa .............. $18-19$

Assim, o serviço civil inglês se estrutura sòlidamente na idéia da carreira; o jovem entra cedo na administração pública e terá oportunidade de galgar os postos administrativos em escala e terá cendente até alcançar o cargo de secretário permanente da classe
administrativa. 
O sistema de classificação de cargos funciona ligado aos sistemas das escolas públicas, secundárias e das universidades; há o cuidado de trazer permanentemente para o serviço público os jovens mais bem dotados do sistema educacional do país. Admitese que os moços que já demonstraram qualidades de inteligência e caráter nos estudos serão os melhores funcionários, serão os que irão ter grande sucesso na vida profissional.

$\mathrm{Na}$ Inglaterra impera o princípio de que o concurso deverá selecionar na base de critérios gerais e humanísticos. O treinamento realizará, depois, a adaptação profissional no tipo de trabalho. Dai a ênfase que assume o sistema de treinamento no serviço inglês, pois constitui complemento integral à formação do funcionário britânico integrante das classes gerais do Tesouro.

As autoridades atestam que, a julgar pelos resultados, o sistema de concurso inglês tem merecido encômios sem conta e que apenas se critica o fato de que muitas vêzes o sistema produz funcionários bons demais para o tipo comum do serviço civil.

\section{2 - Estados Unidos da América}

Descobrir no mercado de trabalho o pessoal que se proponha a ingressar no serviço público, selecioná-lo, retribuir-lhe condignamente o trabalho e aperfeiçoá-lo para proporcionar-lhe acesso, constituiu sempre, em todos os tempos e latitudes, o objetivo principal da classificação de cargos.

Outra preocupação diretora na tarefa de classificar os cargus em tôdas as esferas de govêrno, tem sido a de estabelecer hierarquia, não apenas quanto à remuneração, mas também quanto à dificuldade, importância e responsabilidade do cargo.

Desde 1883, ano em que se introduzia nos Estados Unidos o sistema de mérito, deflagrou-se ali o movimento de elevação dos padrões de eficiência nos serviços públicos norte-americanos, até que em 1912 o governo municipal de Chicago classificou os cargos na base das funções e responsabilidades de cada um dêles.

Estudando o assunto na esfera federal, a partir de 1907, um outro movimento desenvolvia-se, paralelamente, nos Estados Unidos na procura de um meio que permitisse avaliar o grau de eficiência dos servidores públicos, com o fim de facilitar a determinação das variações dos vencimentos, com base no serviço prestado.

O Bureau of Efficiency, instalado para êsse fim, concluiu que, para a boa aplicação de um sistema de apuração de eficiência, era necessário classificar os cargos segundo o seu caráter e valor.

Em 1923 era decretada a classificação de cargos nos Estados Unidos, distribuindo-se as atividades da administração pública 
por grandes grupos, encerrando numerosas classes de graus de dificuldades e responsabilidades diferenciadas, constituidas em séries e grupos unitários reduzidos aos seus justos limites.

O completamento dêsse trabalho pelo "Personnel Classification Board", em 1924, foi continuado pela Divisão de Classiticação da "Civil Service Comission", a partir de 1932, sempre dentro do mesmo ponto-de-vista inicial da consideração dos fatôres: dificuldade, importância, responsabilidade e remuneração.

Como se sabe, a partir daí, as atividades no serviço público norte-americano passaram a se distribuir por cinco grandes grupos
assim denominados:

Serviço profissional e cientifico;

Serviço subprofissional;

Serviço burocrático, administrativo e fiscal;

Serviço de vigilância, conservação, transmissão e transporte;

Serviço de artífices.

Cada "serviço" (no sentido de carreira) compreende um de terminado número de graus de dificuldade e responsabilidade; cada grau divide-se em gêneros de atividade, que são as classes; e cada grupo de classes constitui uma série.

Criando apenas os "serviços" e fixando os graus de cada um, a lei não especificou as classes, incumbência que foi cometida, como já se disse, ao "Personnel Classification Board". (3)

Difere de muito a classificação de cargos dos Estados Unidos da classificação da Inglaterra; naquela prevalece um sistema técnico bem articulado e por vêzes excessivamente minucioso. O sistema inglês se levanta fundamentalmente na classificação de cargos das classes administrativas gerais ou de Tesouro.

Enquanto a técnica da classificação de cargos inglêsa se atém mais a responsabilidades, o sistema americano se preocupa com os deveres. Em essência, o sistema de cargos administrativos da Inglaterra é uma extensão do sistema educacional.

Por outro lado, a classificação inglêsa se levanta sôbre a base de amplas classes administrativas que representam genèricamente grandes divisões de trabalho; dentro de cada divisão ou classe, há verticalidade de atribuições correspondentes a uma escala hierárquica de graus de maiores responsabilidades. Necessàriamente da dos Estados Uç̃ón técnica, conquanto que sui generis, diferente sistema minuciosamente em que a técnica se esmerou, criando um

(3) Astério Dardeau Vieira - Como Classificar os Cargos - In Revista do Serviço Público, de abril de 1941, pág. 5 . 
O sistema inglês derivou-se do sistema educacional coerente com os princípios filosóficos do relatório Macaulay, como já vimos, ao passo que o sistema americano proveio da necessidade de solucionar o problema do custo de vida, portanto, solucionar problema de salário ou vencimento.

Além da diversidade de origens, há ainda outras causas que explicam a técnica esmerada do sistema americano; há, por exemplo, a ênfase que se dá à especialização profissional. Enquanto no sistema americano o recrutamento requer sólido "background" técnico-científico, acompanhado de comprovada experiência, no sistema inglês, ao contrário. o candidato recrutado é um escolar ou acadêmico sem formação especializada e que irá, no próprio trabalho, durante o estágio, receber educação técnica que dê os conhecimentos das funções que deverá desempenhar. (4)

\section{3 - Canadá (5)}

$\mathrm{Na}$ administração canadense, a adocão de um sistema de classificacão dos cargos foi, como nos Estados Unidos, conseqüência de um movimento de ordem geral, que tinha por objetivo a melhoria dos serviços públicos. Enquanto, porém, nos Estados Unidos, já em 1883, adotava-se o "sistema do mérito". o Canadá resistiu ainda quase vinte anos, entrando no século XX sob o regime do favoritismo.

Em 1918, conseguiu-se no Canadá a promulgação da Lei do Serviço Civil, que assinalou o início da restauração administrativa.

Até então, o problema da classificacão dos cargos não tivera melhor sorte que as demais questões relativas à administração de pessoal. Logo após a criação do Domínio do Canadá, uma classificação fôra estabelecida, mas apenas para o "departmental staff".

A impropriedade dessa classificação foi reconhecida através de numerosas investiqacões levadas a efeito e aue não chegaram a produzir um resultado prático. É que como "trabalhador", por exemplo, firuravam funcionários de diversas espécies, pois era êsse o expediente de aue lançavam mão os chefes de serviço para obter pessoal qualificado.

As modificacões, introduzidas antes da promulaacão da Lei तo Servico Civil canadense em 1918. não tiveram maior expressão. A nova lei atacou o problema administrativo sob vários aspectos, inclusive os de classificação dos cargos e remuneração do pessoal.

(4) Poppe - Op. cit. p. 27.

(5) Dardeau - Op. cit. p. 19. 
Determinou que todos os cargos seriam classificados e adotou o principio de "igual remuneração para trabalhos iguais".

Depois de um estudo dos vários tipos de cargos encontrados no serviço, foi estabelecido um padrão de classificação, indicando para cada classe as habilitações necessárias e a remuneração cabivel. Nessas classes foram enquadrados os cargos. Quando se apresenta a necessidade de uma nomeação nova, procede-se a uma análise semelhante, de modo que seja observado, tanto quanto possivel, o principio de igual pagamento por trabalhos iguais.

Como nos Estados Unidos, a classificação de cargos no Canadá, integrante de um movimento de ordem geral, foi colocada em foco através do problema da remuneração. A orientacão semas com Canadá foi, portanto, a mesma dos Estados Unidos, dos servidores.

\section{4 - Pôrto Rico (6)}

$\mathrm{Na}$ então possessão de Pôrto Rico, hoje país independente, adotou-se, em 1936, a classificação yankee com ligeiras variantes, sendo que em vez de cinco "serviços" constituiram-se ali quinze
grupos ocupacionais assim denominados:

Grupo de Agricultura e Biologia

Grupo de Escritório e Administração de Negócios

Grupo de Comunicações

Grupo de Artifices, Jornaleiros e Construtores

Grupo de Atividades Domésticas

Grupo de Economia, Ciências Sociais e Bem-Estar

Grupo de Engenharia

Grupo de Fazenda, Contabilidade e Estatística

Grupo de Vigilância, Prisões e Reformatórios

Grupo de Inspeção e Investigação

Grupo Legal

Grupo de Biblioteca e Instrução

Grupo de Medicina, Hospital e Saúde Pública

Grupo de Museu, Fotografia e Artes

Grupo de Ciências Físicas

Cada um dêsses grupos divide-se horizontalmente em séries de classes. Em sentido vertical, o desdobramento se faz por graus

(6) Dardeau - Op. cit. p. 19 . 
de responsabilidade e dificuldade do trabalho, tendo sido reconhecidos dezessete graus para todo o serviço.

As séries de classes, como a própria expressão indica, são constituídas de classes superpostas, cada uma correspondente a um grau diferente, mas tôdas do mesmo gênero.

O grupo unitário vem a ser, portanto, a classe. Os seus limites laterais são fornecidos pelo gênero de trabalho; os limites inferior e superior são determinados pelo grau de responsabilidade e dificuldade das funções.

A classificação de cada cargo individual se faz pela análise dos respectivos elementos, o que vai enquadrá-lo numa classe qualquer, de acôrdo com a semelhança que apresente com a respectiva especificação.

As diferenças do sistema de classificação de cargos de Pôrto Rico, em relação ao dos Estados Unidos. consistem em pormenores de importância secundária.

\section{5 - França (7)}

Não existe na França uma classificação sistemática de cargos, nem de ordem geral, nem de ordem parcelar. Os cargos vão sendo grupados sem maior exame das respectivas funções e responsabilidades, sem obediência a qualquer plano preestabelecido.

Por um natural espírito de imitação, as denominações vão-se reproduzindo através dos diferentes setores do serviço público,

sem que, entretanto, ao mesmo título correspondam sempre as mesmas funções. Por outro lado, a falta de contrôle permite a multiplicação das desiqnações para funções iquais. O panorama é o mesmo que em 1936 se observava no Brasil e que ainda hoje se verifica na maioria dos nossos Estados e Municípios.

Na França, até certo ponto, dentro de cada repartição o grupamento se faz por gênero de trabalho e por graus de responsabilidade e dificuldade das funções, avaliados sem grande precisão. Diretores, subdiretores, redatores, comissários, expedicionários são grupos geralmente integrantes da escala hierárquica, nas repartições de ordem administrativa. Datilógrafos, estenógrafos, carteiros, telegrafistas são grupos mais ou menos definidos por gênero de trabalho. Não existe, porém, uma compreensão geral do que cada título signifique. Em grande número de casos, trata-se de denominações tradicionais, que vão sendo aplicadas a esmo.

(7) Dardeau - op. cit. p. 21. 
Em suma, o problema da classificação de cargos não foi ainda encarado de frente, na administração francesa. Enquanto nos Estados Unidos e no Canadá, o problema dos vencimentos despertou a atenção para a classificação dos cargos, do que resultou a implantação de sistemas racionais, na França os administradores procuraram resolvê-lo sem atacar aquêle ponto básico, pois as providências consistiram em procurar restabelecer o poder aquisitivo de 1914, mantendo, portanto, as desigualdades resultantes da falta do plano de classificação, e conceder abonos de diversos tipos, inclusive na base de encargos de familia e variações locais do custo da vida.

Em 1926, duas comissões foram instituidas na França para estudar a reclassificação dos cargos e o reajustamento dos salários; a primeira, que ficou encarregada do pessoal da Repartição dos Correios, Telégrafos e Telefones, apenas propôs um aumento sôbre os salários de 1917; a segunda, que deveria reclassificar todos os demais cargos, preferiu seguir a linha de menor resistência e quase nada fêz, limitando-se a condensar os numerosos tipos de vencimentos existentes e, nessa base, procedeu ao reajustamento dos
salários.

O problema de classificação de cargos na França, portanto, continua sem solução e não se tem noticia de que a questão tenha sido atacada na Itália, Argentina ou outra qualquer nação de
lingua latina.

\section{6 - Brasil}

O Brasil, parece, foi o primeiro país da latinidade a encarar o problema da classificação de cargos, porque até agora, apenas algumas pequenas repúblicas centro-americanas (Pôrto Rico e El norte-americano.

É verdade que o sistema de classificação de cargos introduzido no Brasil pela Lei ${ }^{\circ} 284$, de 1936 , só se preocupou com a padronização de vencimentos do funcionalismo, conservando as denominações clássicas dos cargos, grupados em classes distinguiveis pela letra do alfabeto português em ordem sucessiva e pelo escalonamento de padrões de vencimentos mensais e anuais, mas não levou em consideração o conteúdo de cada um dêles.

De então para cá muito se tem dito e escrito sôbre classificação de cargos, constituindo-se a Revista do Serviço Público, editada 
pelo Serviço de Documentação do DASP, no melhor veículo de idéias e pensamentos a respeito do magno assunto.

Assim, em princípios de 1938, Astério Dardeau Vieira descrevia em traços largos a estrutura do funcionalismo público federal nos Estados Unidos. (8)

"Como Classificar os Cargos" foi a tese defendida por êste mesmo autor no primeiro concurso para a carreira de Técnico de Administração, realizado em 1940.

HARVEY WALKER realizou no Brasil, em 1943, uma brilhante conferência sôbre o assunto, sempre dentro das mesmas idéias expendidas no seu Public Administration, dado a lume em New York em 1937. (9)

José Wenceslau do Amaral tratou do problema numa série de artigos, historiando, comparando e apresentando sugestões de importância. (10)

Em 1945, Byron TôRres de Freitas dedicou um capítulo inteiro de um seu livro em que tratou da importância, objetivos, utilidade, técnica e classificação de cargos no serviço civil brasileiro. (11)

Posteriormente, Eduardo Pinto Pessoa Sobrinho tratou do problema nos âmbitos federal, estadual, municipal e no ramo de saúde pública e examinou os aspectos legais de um plano de classificação de cargos no Brasil, em sucessivos artigos divulgados ra Revista do Serviço Público. (12)

José MEDEIros divulgou um excelente trabalho sôbre a história da classificação de cargos no nosso país. (13)

Sôbre análise de cargos e plano de remuneração para fins de classificação, o assunto tem sido também tratado proficiente-

(8) DARDEAu - A Organização do Funcionalismo Federal nos Estados Unidos - In Revista do Serviço Público, fevereiro de 1938.

(9) HaRvey Walker - Classificação de Cargos (Conferência) - In Revista do Serviço Público, dezembro de 1943.

(10) José Wenceslau do Amaral - O Problema da Classificação de Cargos no Brasil - In Revista do Serviço Público - Outubro e novembro de 1944 - Janeiro e março de 1945.

(11) BYRon TôRRES DE FREITAS - Administração de Pessoal - Editôra Pan-americana Ltda. - Rio, 1945, págs. 32/48.

(12) Eduardo Pinto Pessoa Sobrinho - In Revista do Serviço Público - Set./Out. de 1948 - Nov. Dez. de 1948 - Maio de 1950 - Setembro de 1952 - Outubro de 1952.

(13) José Mederros - Classificação de Cargos no Brasil - In Revista do Serviiço Público - Julho de 1952. 
mente por Monteiro Lopes (14), Byron de Freitas (15), Elza de Alvarenga (16) e Felipe Carneiro. (17)

Pinto Pessoa e José de Nazaré Teixeira Dias trataram da questão em base doutrinária e forma didática numa obra que fizeram editar em 1949. Tratando da classificação dos cargos e do funcionário, os autores universalizaram o assunto, dando conceitos apropriados a cargo, classe, carreira, grupo de carreira, serviço etc. (18)

\section{2 - PLANOS DE CLASSIFICAÇÃO DE CARGOS E DE REMUNERAÇÃo}

\section{1 - Bases, equivocos, critica}

De modo geral, a classificação de cargos não representa um fim, como já se disse no ponto anterior, mas um meio administrativo, destinado a facilitar a realização de inúmeros objetivos da administração do pessoal. Um plano de classificação de cargos não passa, pois, de um instrumento da administração no setor
de pessoal.

A classificação, como já vimos, é importante e indispensável, já porque torna uniforme a denominação dos cargos, já porque define os seus títulos, já porque fornece informações concisas acêrca de suas atribuições e responsabilidades, ao dispô-los em ordem lógica de correspondência.

Um plano de classificação de cargos, quando bem elaborado e implantado, constitui base sólida para a elaboarção do plano de remuneração, com o escalonamento sistemático de vencimentos proporcionais ao trabalho executado, o que permite assegurar igual remuneração para trabalho igual, dentro das diversas unidades da organização; auxilia também o órgão centralizado de pessoal no recrutamento e seleção; estabelece linguagem comum no serviço; proporciona aos órgãos de execução recurso preciso para expresfiscais.

(14) Tomás de Villanova Monteiro Lopes - A análise dos Cargos 1949.

(15) BYron Tôrres de Freitas - Análise de um Plano de Classificação de Cargos e Remuneração - In Revista do Serviço Público - Mar./53.

(16) Elza de Alvarenga - Análise do Cargo e seu Reflexo na Classificação - In Revista do Serviço Público - Março de 1953. (17) FRLIPE Carnerro - Análise do cargo de Escriturário - In Revista
do Serviço Público.

(18) Eduardo Pinto Péssoa Sobrinho e José de Nazaré Teixeira Dias Nacional - Rio, 1949, págs. 51/7a de Pessoal - Departamento de Imprensa
- Dinas de 
Há quem diga que a classificação de cargos segrega os cargos em compartimentos estreitos, estanques, restringindo assim as oportunidades de promoção dos funcionários para trabalho de maior dificuldade no mesmo setor ou a transferência dos mesmos de um setor de trabalho para outro. Não é verdade. Os processos de classificação nada mais fazem do que analisar cargos, tal como existem, e colocá-los na mesma classe que outros substancialmente semelhantes em atribuições e responsabilidade. Quer dizer, refletem simplesmente os fatos.

Quanto à admissão do pessoal, isto é, a seleção de pessoal na base das respectivas qualificações para funções e responsabilidades, mais elevadas ou diferentes, o plano de classificação de cargos, por meio de descrições dos trabalhos individuais, proporciona informações exatas e pormenorizadas quanto às atribuições a ser desempenhadas e, por meio de especificação de classe, indica as exigências mínimas de qualificação para as várias classes de cargos. O confronto entre essas exigências de qualificações e as qualificações de fato apresentadas pelo funcionário de cuja promoção se cogita não é função de classificação, mas de colocação do pessoal a qual pode ser ou não rigorosamente controlada, dependendo das praxes do departamento e das regras que regulam a colocação.

Se, com referência às normas de recrutamento e colocação do departamento, ou como parte dos regulamentos do serviço civil, se estabelecessem regras muito limitadas de promoção na base das classes fixadas, dificultando o acesso de uma classe para outra, ou a transferência de uma carreira para outra, a passagem dos funcionários pelos vários degraus da carreira ficaria prejudicada; neste caso, porém, a culpa caberia aos regulamentos e normas e não ao plano de classificação de cargos.

Observando-se que as exigências de qualificação, expressas nas especificações de classes, estão estatuídas de modo inadequado ou demasiado restrito para proporcionar as devidas oportunidades de promoção aos integrantes do serviço, há um remédio para tal situação, que é a reelaboração dessas exigências ou revisão dos padrões de qualificação. Na realidade, uma das funções rotineiras inerentes à manutenção do plano de classificação de cargos é o estudo constante dos resultados da aplicação das exigências de classificação contidas nas especificações de classes, e sua revisão, sempre que necessário ou conveniente.

O de que não resta dúvida é que a classificação de cargos auxilia, ao invés de prejudicar, os processos de promoção, pois proporciona a base para a determinação das linhas de promoção e para o desenvolvimento de outras, para a definição das carreiras, para a organização de cursos de treinamento, destinados a preparar 
os funcionários a funções mais elevadas, para identificar os funcionários que se encontrem em funções inadequadas e colocá-los em cargos para os quais sejam mais indicados e para determinação de onde existem, no serviço, fontes reais ou potenciais de suprimento para preenchimento de cargos de certo tipo.

O funcionário ambicioso procura informar-se sôbre as possibilidades de promoção e de como pode qualificar-se para êsses cargos de grau mais elevado. As especificações respondem a essas indagações. O conhecimento geral das atribuições de um cargo não basta para estabelecer-se um programa de melhoria própria, sendo necessário recorrer-se a informações mais pormenoriza-

Os pessimistas afirmam, às vêzes, que a classificação de cargos pode tornar -se impraticável, de vez que os cargos e suas atribuişões e responsabilidades estão sempre mudando.

De fato, com o correr do tempo, em qualquer setor da administração, novos cargos são criados, atribuições e responsabilidades modificam-se substancialmente, ou extinguem-se até. Por outro lado, algumas classes e especificações de classes podem tornar-se obsoletas, devido a modificações ou desenvolvimento das atribui-
ços e responsabilidades dêsses cargos.

O plano de classificação de cargos encara essas condições. prevendo as necessidades e estabelecendo métodos de ação e normas, não só para o presente como para o futuro. Como parte integrante do plano deverá haver um código de regras formais e fundamentais para a sua instalação e manutenção e para a interpretação, emenda e alteração das especificações de classe, a fim de tentempanhar as modificações do serviço e dos cargos neste exis-

Assim, um plano de classificação de cargos deve conter em si normas para o seu continuo crescimento, de forma a manter. efetiva e sistemàticamente, um esquema permanente e normal, com a descrição das classes de cargos que se aplicarão nos cargos

Um plano de classificação de cargos não deve se fixar e permanecer inalterável em determinado tempo e sim tornar se ativo e crescente, de acôrdo com as tendências do próprio serviço.

Para se chegar sistemàticamente à solução dos problemas de remuneração, direção e recrutamento de pessoal, faz-se mister que aos cargos correspondentes ao mesmo trabalho seja aplicada a
mesma escala de remuneração e exigida a mesma qualificação.

Conseqüentemente, as diferenças no trabalho dos vários cargos devem refletir nas diferenças das escalas de vencimentos e nas 
exigências de qualificação. Para se aplicar esta norma a cargos individuais será necessário:

1) identificar e grupar prèviamente os cargos que correspondem a trabalho igual, fixando, por conseguinte, igual escala de remuneração e exigindo as mesmas qualificações;

2) determinar a direção e extensão das diferenças entre êsses grupos, isto é, se um é superior ou inferior a outro e em que proporção.

Antes de se chegar a uma conclusão quanto à remuneração e às exigências de qualificação, será necessário dispor-se de padrões de referência, para serem utilizados na comparação entre os cargos individuais.

Fazer essas identificações e estabelecer êsses padrões de referências é que é classificar os cargos na base fundamental já citada, que é a das atribuições e responsabilidades habituais dos cargos.

Assim, adota-se o trabalho de cada cargo como base para : respectiva classificação; coloca-se na mesma classe os cargos que correspondam a trabalho semelhante que exija igual tratamento; dispõem-se tôdas as classes de cargos, segundo a espécie de trabalho e por ordem de dificuldade e responsabilidade, de modo a mostrar como cada classe de cargos está ligada, sob êsses pontos-de-vista, a tôdas as demais; prepara-se assim o terreno sôbre o qual se possa, de modo sistemático, seguro e adequado, decidir sôbre as escalas de vencimentos e as qualificações a serem exigidas.

Conclusão: a classificação de cargos não tolhe, como se pensa, a liberdade dos administradores e supervisores na distribuição de serviço e delegação de responsabilidades entre os funcionários sob sua direção.

As classes e especificações de classes, compreendidas no plano de classificação de cargos, devem ser descritivas e não restritivas. Esses planos não se destinam a criar sistema rígido de classes que não podem ser alteradas e às quais os cargos e atribuições dos funcionários deverão conformar-se sempre. Seu papel não é limitar ou especificar as espécies de cargos, que podem ser criados de vez em quando, nem determinar, controlar ou indicar as atribuições que determinado funcionário desempenhará, ou as responsabilidades que lhe caberão; outrossim, sua finalidade é caracterizar cada classe de cargos, com atribuições e responsabilidades de modo que os cargos individuais se enquadram em sua respectiva classe.

A distribuição de tarefas e delegações de responsabilidades não devem ser reguladas pelo plano de classificação de cargos 
e sim pelas autoridades administrativas ou supervisoras investidas de autoridade para fazerem a distribuição do trabalho e delegarem as responsabilidades. (23)

\section{2 - Considerações gerais; recomendações especiais}

A nossa opinião pessoal é de que uma comissão que, em qualquer nivel de govêrno, seja designada para a elaboração de um plano de classificação de cargos e revisão dos niveis de remuneração pode e deve desempenhar a sua difícil e imensa tarefa, levando em boa conta os seguintes aspectos e considerações:

I - Adotar um sistema de classificação eclético adaptável ao nosso espírito latino e não copiar servilmente o que sôbre o assunto exista alhures. Que os modelos anglo-americanos e outros
nos sirvam apenas de base.

II - A classificação de cargos não pode se preocupar apenas com a situação presente, mas em preparar o plano em razão do futuro; quer dizer, analisados os cargos e funções, construido o plano, especificadas as séries ideais com as respectivas faixas de vencimento, as qualificações exigidas etc., e tendo em vista que a comissão do plano, certamente, não irá propor melhorias imediatas nem promoções automáticas, os quadros ou esquemas do país, do Estado ou do municipio, no Brasil, como primeiro grande país do mundo latino a adotar planos de classificação de cargos, devem
ser feitos em consideração do porvir.

III - Cumpre reduzir ao minimo extranumerários, circunscrevendo os tivo e subprofissional e enquadran em quadros subadministracujo final corresponda ao iniciando-os numa faixa de salás dita, tanto na esfera federal, colal da carreira civil, pròpriamente

IV - Para o estadual e municipal. profissional dever ingresso nos quadros subadministrativo e sub-

$V$ Constir conclusão de curso especial.

faixas de vencimentos quadros ideais de classificação de cargos, ções exigidas.

VI - Evitar duplicidade de denominação dos cargos e a assistemática nesta parte da questão.

VII - A exemplo do gue-se o sistema de classifica ocorre na carreira militar, conjucional próprio para o resificação de cargos com o sistema educacivil, criando escolas de

(23) BARUCH - Op. cit. na citação (1) 
municipal, de nível universitário, constituida de cursos de três anos de duração e compostos de disciplinas especificamente administrativas, para cujo ingresso fôsse exigido, além do certificado de conclusão de curso de segundo grau, o concurso de habilitação (vestibular).

VIII - A par da formação de administradores nessas escolas, que se continuasse com a seleção por meio de provas e títulos para os cargos técnicos, científicos, de magistério, inspectivos, subalternos etc.

IX - Paralelamente às denominações dos postos nas Fôrças Armadas, que se dêem aos cargos civis denominações que exprimam, de fato, a natureza do trabalho, a posição ocupada pelo cargo na estrutura do serviço público civil e o seu grau de dificuldade.

$\mathrm{X}$ - Todos os cargos e funções encontrados na ocasião do levantamento para construção do plano poderiam ser enfeixados em:

\section{a) Administração Superior}

Serviço Administrativo;

Serviço Técnico-Administrativo;

Serviço Técnico-Cientifico;

Serviço Técnico-profissional, todos do mesmo nivel;

b) Administração Inferior

Serviço Subadministrativo;

Serviço Subprofissional, ambos de igual nivel.

XI - Se outras denominações genéricas não pudessem ser encontradas na nossa terminologia administrativa, que se tomassem por base as seguintes:

a) $\mathrm{Na}$ Administração Superior:

Aspirante a Oficial Civil Adjunto de Administração Auxiliar de Administração Assistente de Administração Assessor de Administração Vice-Oficial Administrativo 3. Oficial Administrativo

2. Oficial Administrativo

1. Oficial Administrativo Oficial Maior de Administração
Aspirante a Contador

Contabilista-Adjunto

Contabilista-Auxiliar

Contabilista-Assistente

Contabilista-Assessor

Vice-Contador

3. Contador

2. Contador

18 Contador

Oficial Maior Contador (ou Contador-Chefe) 


\section{b) $\mathrm{Na}$ Administração Inferior:}

1) Serviço Subadministrativo

Praticante de Escritório

Escrevente Administrativo

3. Escriturário

2. Escriturário

1. Escriturário

Escriturário-Mor

Suboficial Administrativo
2) Serviço Subprofissional Aprendiz de Eletricidade Ajudante de Eletricidade 3. Eletricista 2. Eletricista $1{ }^{\circ}$ Eletricista Eletricista-Mor Suboficial Eletricista

XII - Com êste critério desapareceriam as atuais classes literais ( $A, B, C$ etc. ), as referências numéricas $(1,2,3$ etc.), os símbolos alfa-numéricos ( $\mathrm{A}-1-13-27)$ e com estas convenções, pouco a pouco, a idéia da classe Adjunto do serviço civil ligada civil correspondendo-Tenente das Fôrças Armadas; Assistente diante, associar-se-ia muititar no pôsto de Capitão e assim por vidores nas suas referências verbais fàcilmente no espírito dos serXIII - Na aderências verbais ou escritas.

uma faixa conten administração superior deveria ser, assim, fixada uniformes para todos os 4 servicinicial e o teto, com 9 acessos

XIV

forma, fixada uma faixastração inferior deveria ser, por outra limitado ao padrão inicial contendo o vencimento inicial e o teto com 6 acessos uniformes fixado para a administração superior, possibilidade de galgar os postos na adming serve ainda com a diante a satisfação das exigências na administração superior, me-

XV - Nestas con exigências requeridas.

dos serviços da adminições, qualquer ocupante da última classe sempre um aspirante às classes inferior, isto é, o suboficial, será rior, podendo até concorrer correlatas da administração supequalquer posição em que se en cargos desta, como é óbvio, de contanto que satisfaça os requentrar na administração inferior, quela.

XVI

requisitos exigidos para o ingresso naverificassem regularmente.

Diante dessas idéias, ocorre-nos indagar: será racional a
estrutura geral das Fôrças Armadas? estabilidade da situação no decormadas? Parece que sim, dada a $O$ ingresso nas Fô decorrer de séculos. das seguintes formas:

a) convocação;

b) voluntariado; 
c) curso de especialistas;

d) concursos;

e) cursos de nível universitário;

f) cursos de especialização superior.

Por convocação ou voluntàriamente o servidor pode galgar os seguintes postos de denominação precisa, gradação uniforme e salários mensais fixos:

Soldado (praça de pré)

Cabo

$3{ }^{\circ}$ sargento

$2^{\circ}$ sargento

$1 \%$ sargento

Sargento-ajudante

Subtenente

Constituem êstes a grande classe de extranumerários, por assim dizer, do serviço público militar.

Por concurso admite-se pessoal técnico ou de nível superior (médicos, farmacêuticos, dentistas etc.); mediante cursos de especialistas dá-se o ingresso no serviço militar de profissionais diversos, como mecânicos, eletricistas, escafandristas, pontoneiros, controladores de vôo, aerofotogrametristas etc.; mediante cursos de especialização superior os oficiais de curso de guerra em terra, no mar e no ar, garantem o ingresso no generalato. É mediante - curso de nível universitário que se dá o ingresso na verdadeira carreira militar com postos de denominação também precisa, gradação racionalmente uniforme e vencimentos mensais fixos: Brigadeiro

General-de-Exército - Almirante-de-Esquadra - Tenente-

General-de-Divisão - Vice-Almirante - Major-Brigadeiro

General-de-Brigada - Contra-Almirante - Brigadeiro

Coronel - Capitão-de-Mar-e-Guerra.

Tenente-Coronel - Capitão-de-Fragata.

Major - Capitão-de-Corveta.

Capitão - Capitão-Tenente.

1: Tenente

2. Tenente

Aspirante a Oficial

A Academia Militar das Agulhas Negras mantém cursos das armas de Infantaria, Cavalaria, Engenharia e Artilharia e Curso de Intendência; a Escola de Guerra Naval ministra cursos de Aspirantes a Guarda-Marinha, a Fuzileiro Naval e a Intendente- 
Naval; cursos de oficiais aviadores, oficiais de Infantaria de Guarda e de Intendentes são mantidos pela Escola de Aeronáutica.

Por que não adotar o mesmo regime, as mesmas normas, os mesmos métodos no serviço civil?

Parece recomendável, então, que:

1 - $O$ ingresso para a Administração Superior ficasse condicionado:

11 - No Servico Administrati diploma de curso estadual ou municipal. A matrícule três anos na escola nacional, ou nada ao concurso de escola estaria condiciotação do certificado de conilação (vestibular), mediante apresen-

12 curso secundário de $2^{\circ}$ grau. competitivo público.

13 - No Serviço Técnico-Profissional: idem.

14 - No Serviço Técnico-Científico: mediante apresentação de diploma de curso superior e concurso de provas e de títulos
ou defesa de tese:

2 - Na Administração Inferior:

21 - No Serviço Subadministrativo: mediante apresentação de certificado de conclusão em curso de especialidade. Subadmiperior, os porque da mesma forma como na Administração Sucapacidade de direção cargos na Administração Inferior terão desde o aprendiz ou pristo como numa linha de acesso que vai de comando iria crescendo grade até a suboficial, esta capacidade garem os postos da Adminiativamente, capacitando os a galFôrças Armadas de todministração Superior, como acontece nas

22 - No Servidos-membros. assim estruturadas:

a) No Serviço Subprofissional:

1. De Aprendiz Artifice a Suboficial Artifice

3. De Aprendiz de Máquinas a Suboficial Maquinista dar-se-ia para de todos os grupos do Serviço Subprofissional e Técnico-Cientifico. 
b) No Serviço Subadministrativo:

1. De Praticante de Escritório a Suboficial Administrativo

2. De Praticante de Almoxarifado a Suboficial Almoxarife

3. De Praticante de Arquivo a Suboficial Arquivista

4. De Praticante de Biblioteca a Suboficial Bibliotecário

5. De Praticante de Documentação a Suboficial de Documentação

6. De Praticante de Estatistica a Suboficial Estatístico

7. De Praticante de Orçamento a Suboficial de Orçamento

8. De Praticante de Organização a Suboficial de Organização

9. De Praticante de Ensino a Suboficial de Ensino

10. De Praticante de Fiscalização a Suboficial de Fiscalização.

O acesso de todos os grupos do Serviço Subadministrativo dar-se-ia para os grupos afins dos Serviços Administrativo e Técnico-Administrativo.

\section{c) No Serviço Administrativo:}

1. De Aspirante a Oficial Civil a Oficial Maior de Administração

2. De Aspiramte a Contador a Oficial Maior Contador

3. De Aspirante a Diplomata a Embaixador etc.

d) No Serviço Técnico-Administrativo:

1. De Aspirante a Almoxarife a Oficial Maior Almoxarife

2. De Aspirante a Arquivista a Oficial Maior Arquivista

3. De Aspirante a Bibliotecário a Oficial Maior Bibliotecário

4. De Aspirante a Documentador a Oficial Maior de Documentação

5. De Aspirante a Estatístico a Oficial Maior Estatístico

6. De Aspirante a Orçamentista a Oficial Maior de Orçamento

7. De Aspirante a Organizador a Oficial Maior de Organização etc.

e) No Serviço Técnico-Profissional:

1. De Aspirante a Meteorologista a Oficial Maior de Meteorologia

2. De Aspirante a Telegrafista a Oficial Maior Telegrafista

3. De Aspirante a Postalista a Oficial Maior de Correios

4. De Aspirante a Coletor a Oficial Maior Coletor 
5. De Aspirante a Galvanoplasta a Oficial Mainr de Galvanoplastia etc.

\section{f) No Serviço Técnico-Científico:}

1. De Aspirante a Advogado a Oficial Maior Advogado

2. De Aspirante a Médico a Oficial Maior Médico

3. De Aspirante a Engenheiro a Oficial Maior Engenheiro

4. De Aspirante a Agrônomo a Oficial Maior Agrônomo

5. De Aspirante a Atuário a Oficial Maior Atuário

6. De Aspirante a Astrônomo a Oficial Maior Astrônomo

7. De Aspirante a Biologista a Oficial Maior Biologista

8. De Aspirante a Dentista a Oficial Maior Dentista

9. De Aspirante a Técnico de Administração a Oficial Maior Técnico de Administração etc.

\section{3 - Condensação e conclusões finais}

Tentemos, agora, condensar em poucas palavra o que aqui se explanou prolixamente:

1 - Nos países anglo saxônicos, a classificação de cargos, ou "positions", como ali se denomina o conjunto de atribuições individuais, para cujo desempenho se exige tempo parcial ou integral de trabalho, é de uso indeclinável em matéria de administração de pessoal, podendo-se mesmo afirmar, no que respeita aos Estados Unidos, que já não existe serviço de pessoal de larga jurisdição, onde não se empregue essa técnica de organização do tra-
balho. (28)

2 - O emprêgo da classificação no cargo da administraçäo de pessoal é instrumento que, embora ainda se não haja tornado perfeito, possui importância básica no funcionamento dos demais processos de trabalho nesse terreno, tais como seleção, treinamento, fixação de salário, orçamento e planificação. (29) 3 - Não menos categóricos são os têrmos em que se refere
ao alcance da classificação de cargos na administração de pessoal
o deputado Mem de Sá, no brilhanto o deputado Mem de Sá, no brilhante relatório apresentado, em aos Estados Unidos da Amébre o assunto, durante a sua viagem

(28) FRED TELFORD - The Classification and Salary Standardization Movement in the Public Service, in Annals of American Academy of Political
and Social Science - London, 1924, p. 113.

(29) Milton M. Mandell - Elements

Public Administration. 1946 
4 - Não difere substancialmente o conceito lógico de classificação do sentido que se atribui a êsse têrmo em administração de pessoal: "repartição de um conjunto de objetos em certo número de conjuntos parciais coordenados e subordinados". (30)

5 - Classificar é, pois, agrupar na mesma classe coisas semelhantes segundo uma ou mais caracteristicas, e reunir em classes diversas coisas que não possuem essas características. Tais características são o que se chama a base da classificação. No tocante ao serviço público, a base da classificação é o cargo, que, por sua vez, se define como sendo o conjunto de atribuições individuais, para cujo desempenho se exige tempo integral ou parcial de trabalho, mediante retribuição pecuniária, correspondente a vencimento padronizado.

6 - Eleito o cargo como base da classificação, consiste o segundo momento desta em reunir em grupos de igual denominação os cargos que, entre si, apresentem similitude, quanto às atribuições que lhes são próprias, às características apresentadas, e aos requisitos para provimento, nêles compreendidos os respeitantes à área sôbre a qual se deva exercer o recrutamento de seus ocupantes.

O grupo ou classe é, desta sorte, a reunião de cargos suficientemente assemelhados quanto às atribuições e posição hierárquica para justificar:

a) o uso de um mesmo título que designe, com clareza, todos os cargos nêle compreendidos;

b) a exigência, para o seu provimento, do mesmo grau de instrução, de experiência e capacidade, e o emprêgo, na seleção dos candidatos aos cargos dêle integrantes, de provas de igual natureza e do mesmo teor de especialização profissional;

c) o estabelecimento de retribuição igual à deferida pelo desempenho de trabalho em condições idênticas.

Todos êsses elementos hão de ser considerados, na tarefa classificadora, pois que nêles se resume o princípio fundamental dessa técnica de organização. Não basta, entretanto, para a integração de dois ou mais cargos num grupo, que entre êles exista identidade sòmente quanto a uma ou mais de uma dessas condições. A formação do grupo pressupõe, ao contrário, conjunto de cargos ligados entre si pela presença de tôdas aquelas notas, cuja existência concomitante dá, pois, o conceito lógico dessa unidade fundamental da classificação.

7 - Dispostos os cargos em grupos e estabelecidas entre êstes as relações que se fizerem aconselháveis, em face da conveniência

(30) A. Lalande - Vocabulaire de la Philosophie, tomo I, p. 109. 
da administração de pessoal, pode complementar-se, ainda, a classificação de cargos, mediante a distribuição dos grupos em ser-
viços.

Esta terceira fase de trabalho não pertence, entretanto, à essência da classificação. O processo de situar os grupos em serviços, segundo o caráter genérico das atribuições dos cargos integrantes daquela unidade fundamental do sistema de classificação reveste, porém, manifesta utilidade no desenvolvimento dessa técnica de divisão do trabalho, notadamente no que diz com a sua apresentação nos órgãos administrativos e legislativos.

8 - As noções de cargo, grupo e serviço são, pois, imanentes ao conceito de classificação, que, reduzida a seus têrmos mais simples, se pode dizer que é a "técnica pela qual se verificam, mediante coleta e análise de dados concernentes às tarefas executadas no serviço civil, quais os diferentes grupos de cargos que demandam tratamento diferenciado na administração de pessoal". 9 - Entre cânones fundamentais da classificação de cargos avulta o que manda ter em conta, nesse trabalho, sòmente dados objetivos. O que importa classificar, segundo êsse principio, é o

A qualificação subjetiva do ocupante do cargo, por certo, não é de somenos; pelo contrário, assume ela particular relêvo em outros momentos do processo de administração de pessoal.
Enquanto atividade classificadora, a administração de pessoal há de ter em conta, porém, exclusivamente operações ocupacionais revelexclusivamente, dados relativos às Torna se imprescindivel, reveladas pelo levantamento realizado. interpretação e no uso portanto, repisar constantemente que, na cumpre ter sempre presente sistema de classificação de cargos, e não o desempenho, aptid que o objeto da análise é o trabalho o executa, nem tampouco, a caracteristicas pessoais de quem do cargo. (31)

$10-A$

mento em cargo de possuida por qualquer pessoa para provipenho das atribuições correspona classe, sua eficiência no desemespecifica que deva receber dentrites a êsse lugar e a retribuição critos para o grupo, as condições dos limites de estipêndio presnivel superior, bem com condiços para a imissão em cargo de requerem exame e tratamo para transferência, são questões que

11 - Noutras parte. (32)

dos processos de administra distingue-se a classificação de càrgos

Management Review de julho Position Analysis and Classification, in The

(32) Joint Commitre de 1935, p. 205.

Report on State Administrative Agencies IN THE Public Service of OHio 
de pagamento e aperfeiçoamento, bem como dos que respeitam à movimentação do pessoal dentro dos quadros do serviço, seja mediante recrutamento preferencial para cargos de nivel superior, seja mediante transferência para lugares de igual nivel.

Pode ocorrer, assim, que o ocupante de um cargo possua aptidão superior à exigida para o desempenho das atribuições competentes ao lugar em que se ache titulado; tal circunstância não dispõe, contudo, a rigor, dos princípios que regem a classificação, de virtualidade para configurar-lhe o cargo, no sistema classificado, de forma cutra que não a resultante da análise objetiva das operações funcionais na realidade desempenhadas.

O tratamento pecuniário que venha sendo conferido ao cargo não detém potencialidade, de igual sorte, para dar-lhe feição discrepante da imposta pelo seu conteúdo ocupacional, pois que, em matéria de classificação, o primado é daquilo que o servidor faz, dos encargos que, de fato, lhe incumbem.

12 - Além de não se dever confundir o cargo com o seu titular, cumpre não envolver no mesmo conceito, classificação e plano de pagamento, uma vez que entre êsses processos há diversidade de base, de objetivo e de técnica.

13 - A classificação diz respeito à integração de cargos $\mathrm{em}$ grupos, segundo as suas atribuições, ao passo que o plano de pagamento, organizado em moldes comutativamente justos, supóe, desta forma, a existência de sistema classificado; mas êste pode existir sôbre si, independentemente de escala de estipêndio, relativamente a cuja organização reveste êle, na técnica de administração de pessoal, o caráter de prioridade lógica.

14 - Longe de apresentar-se como fim em si mesmo, pois, a classificação aparece, no campo da administração de pessoal, como instrumento ou meio, destinado a propiciar a consecução de múltiplos fins ou objetivos, mediante a denominação uniforme dos cargos integrantes do serviço civil, a especificação condensada de suas atribuições, bem como o estabelecimento de relações entre os cargos de acôrdo com esquemas lógicos.

15 - No quadro das noções principiológicas informativas do sistema classificado situa-se, ainda, e não entre as menores, repetimos, a que impõe a continuidade do trabalho classificador, de forma a mantê-lo sempre atualizado; não só o surgimento de novos encargos na área administrativa exige, na verdade, a todo o momento, a criação de novos cargos, como ainda, a alteração das atribuições dos cargos existentes e da qualificação exigida para o seu desempenho demandam a reclassificação dêles, a fim de que o sistema se mantenha sempre vivo, atuante e proporcionando às exigências constantemente renovadas do serviço. 
16 - Entre os principios fundamentais do processo de classificação de cargos, como já se disse, há o que diz respeito à inspeção permanente da área classificada, a fim de se registrarem as alterações nela operadas e de se proporem medidas tendentes a manter e aperfeiçoar a estrutura do sistema. É que a fisionomia do quadro de pessoal não se conserva imutável; transforma-se continuamente, tanto em face do acréscimo de atribuições e conseqüentemente criação de novos serviços, como pela supressão de numerosas atividades ou modificação de atribuições de cargos

17 - A classificação não imprime feição definitiva ao cargo, yue fatôres ligados à própria habilitação profissional de seu ocupante não possam modificar; os chefes de serviço guiam-se sempre, na distribuição dos encargos existentes, de preferência, pelo conhecimento que têm da capacidade dos servidores a êles subor-
dinados.

Essas circunstâncias induzem a ligar a sorte de qualquer plano de classificação de cargos à maneira como fôr administrado pelo órgão especialmente encarregado dessa tarefa.

Portanto, para desempenhar as funções decorrentes da contínua administração do plano de classificação de cargos é necessário, pois, que se designe ou se crie um órgão de estado-maior ("staffif") para exercer, na qualidade de departamento central de tação. (33)

18 - Na ordem administrativa municipal, tal competência terá que ser deferida, necessária e irrecusàvelmente, a um departamento municipal do serviço público. A êste departamento, pois, é que o projeto deve conferir o encargo de administrar o plano, não só prescrevendo os projetos que visem criar, transformar, reclassificar, ou extinguir cargos, bem como alterar-lhes padrões ouvido aquêle órgão, sem ser encaminhados à assembléia legislativa, o plano de classificação de cargompir-lhe o encargo de implantar

Há mais de vinte anos passados defendiam -se teses que por serem atualissimas, passaremos a condensálas para os leitores
dêsse trabalho. (34)

(33) Committee on Position-Classification and Pay Plans in THE PubLic SERVICE - Relatório apresentado à Civil Service Assembly of the (34) DARDEAU - Op. cit., pág. $43 / 45$. 
1 - Diversas bases podem servir a classificar os cargos, inclusive a variedade das respectivas funções, mas a única verdadeira é a base dos deveres e responsabilidades.

\section{2 - A classificação dos cargos é indispensável:}

a) a um sistema equitativo de remuneração, com o qual não se confunde;

b) a um sistema de carreira.

3 - A classificação é de grande utilidade:

a) para a seleção e o treinamento;

b) para a elaboração orçamentária;

c) para o contrôle das despesas;

d) para estudos estatísticos;

e) para uma boa administração de pessoal, enfim.

4 - Em diversos países tem-se produzido um movimento no sentido de classificar os cargos, sendo que, nos Estados Unidos e no Canadá, êle tem sido parte integrante de um outro mais geral, cuja finalidade é aumentar a eficiência dos serviços públicos. A necessidade de classificar os cargos é posta em evidência sempre que se procura estudar o problema da remuneração.

5 - O tipo norte-americano de classificação foi determinado pelo interêsse em observar o principio de igual remuneração para trabalhos iguais. Daí se originou a classificação, em duplo sentido: horizontal, por gênero e espécie de trabalho; vertical, pela gradação de dificuldade e responsabilidade, de modo a evitar que fôssem igualmente classificados os cargos que merecessem tratamento desigual.

6 - Pelo mesmo motivo, o sistema típico norte-americano compreende a descrição das funções próprias de cada classe; a análise de cada cargo, antecipadamente à sua classificação; revisões constantes, pelas quais se possa ajustar a classificação às transformações que cada cargo venha a sofrer.

7 - Na Inglaterra, o problema foi encarado mais do pontode-vista da seleção, com o pensamento voltado para o sistema educacional do país. Por isso mesmo, o rigor é menor. As classes foram constituidas com maior amplitude, em correspondência às etapas de educação da mocidade. Não obstante, o sistema inclui o reconhecimento de sucessivos graus de dificuldade e responsabilidade.

8 - No Brasil, a classificação é recente. Como na América do Norte, vem sendo parte integrante de um movimento no sentido da melhoria dos serviços públicos. Ainda à semelhança dos Estados Unidos e Canadá, a sua necessidade vem sendo compreendida através da questão dos vencimentos. 
9 - A orientação até agora seguida, porém, diverge totalmente. O sistema que vimos adotando desconhece as variações de dificuldade e responsabilidade em cada gênero de trabalho, exceto em pouquíssimos casos.

10 - A explicação encontra-se na escassez de tempo com que, geralmente, temos feito a classificação de cargos. O sistema federal, que tem servido de inspirador às outras esferas administrativas, foi elaborado em circunstâncias que exigiam a terminação em curto prazo, incompativel com o pormenor que caracteriza o tipo norte-americano.

11 - Verifica -se, pois, que o movimento tem produzido efeitos variados em diferentes paises, parte em virtude da diversidade de origens, parte em razão de circunstâncias ocasionais .

12 - Dos tipos de classificação encontrados, o que mais satisfaz é o norte americano, que permite liberdade de ação aos chefes de serviço e fornece base sólida para o tratamento de questões vitais de administração de pessoal, tais como a seleção e o treinamento, a remuneração equitativa e a implantação do sistema

13 - O tipo inglês, não apresentando o mesmo grau de precisão, concorre, em menor escala, para a solução dos nossos pro-
b!emas.

14 - O tipo que vimos adotando, em grande parte, tolhe, sem proveito, os movimentos dos chefes de serviço; não presta à seleção e ao treinamento o mesmo auxílio que o norte-americano; conduz a iniqüidades na retribuição do trabalho; e impede a existência de um verdadeiro sistema de carreira.

15 - Conseqüentemente, cumpre substituílo por outro, que siga as linhas mestras do tipo norte-americano

16 - Nada contra-indica essa providência, já desaparecidas aquelas circunstâncias desfavoráveis a um trabalho mais extenso
e profundo.

17 - O momento é oportuno, dado o interêsse que vários Estados vêm demonstrando em normalizar a administração de
pessoal nos moldes da União.

18 - É de tôda a conveniência, portanto, que se comece pela administração federal, não só para seu próprio benefício, mas, também, em virtude da influência que exerce sôbre as demais esferas administrativas do pais.

19 - O trabalho deve ser iniciado o mais breve possivel, para que desde logo se modifique o sentido da influência federal. Deve transcorrer, porém, com calma bastante para que não se comprometam os resultados. 
20 - O exame deve ser orientado por um questionário onde se focalize o máximo de aspectos que possam influir na classificação. As observações deverão traduzir-se em descrição objetiva e análise de cada cargo, facilitada pelos quesitos.

21 - Grande cuidado deverá ser empregado na preparação do questionário, que cumpre fazer acompanhar de instruções minuciosas para o preenchimento. Da experiência já colhida, no país e no estrangeiro, podem ser extraídas sugestões de grande utilidade.

22 - Obtidos os dados, a análise comparativa dos cargos conduzirá à identificação das classes, bem como à sua posição relativa no conjunto. Será a oportunidade para corrigir o defeito visceral do sistema vigente, a amplitude excessiva dos grupos unitários.

23 - A elaboração completar-se-á com a escolha de titulo e a descrição das funções de cada classe.

24 - Simultâneamente à instalação do nôvo sistema, deverão ser tomadas diversas providências de adaptação, referentes a outros aspectos da administração de pessoal, em que a classificação repercute. É mister que os trabalhos sejam acompanhados de estudos paralelos, orientados nesse sentido.

25 - A implantação deverá ser feita mediante lei que aprove as linhas mestras do sistema. Ao Poder Executivo caberá tomar as medidas complementares, inclusive reclassificar os cargos existentes no momento, para o que devem ser mantidas atualizadas as informações colhidas.

26 - Para conciliar a flexibilidade, que deve caracterizar o sistema, com a conveniência de criar certos cargos por lei, basta que se dê ao Poder Executivo competência para proceder permanentemente à reclassificação dos cargos. Os antecedentes autorizam essa medida.

27 - Sempre que conveniente, os cargos deverăo ser criados por lei. De qualquer forma, a classificacão deve ser determinada pela análise das funcões, que será repetida a intervalos, para garantia de que a classificação corresponda aos fatos. Em todos os casos a reclassificacão deve ser feita por ato executivo.

28 - Para elaborar o sistema, implantá-lo e manter a classificacão atualizada, deve ser criada uma divisãn ou outro óraão de classificacão dentro do departamento centralizador das atividades de administração geral.

29 - A despesa que da execução dêsse plano advir justificar-se-á perfeitamente pelas inúmeras vantagens que acarretará, superiores às de outras medidas que vêm sendo tomadas, com igual dispêndio, para beneficiar a administração pública. 
30 - A mesma atuação deverá ser desenvolvida nas administrações locais, por meio de uma ação direta do govêrno federal, cujo exemplo, aliás, é de esperar que se reproduza espontânea-

31 - Assim ter-se-á introduzido e generalizado no pais um tipo de classificação de cargos que, permitindo liberdade de ação tões referentes a pessoal recuperação, seleção e treinament tente para os problemas de sistema de carreira. 